\title{
A Histological Observation of a Coelacanth
}

\author{
(Latimeria chalumnal)
}

\author{
by \\ Sohiti ISOKAWA,* Yoshihisa TODA* \\ and Kimio KUBOTA*
}

A coelacanth was presented by the French Government to Mr. SHORIKI for his efforts with the cultural exchange between Japan and France. It was his idea to first exhibit the fish to the general public at the Yomiuri park managed by him. However, he also hoped that the fish would be observed by Japanese ichthyologists. Therefore, his permission for the dissection was given to the ichthyologists providing they could dissect the coelacanth without injuring its external appearance.

On July 2nd. 1967, the fish was dissected by several scholars. They consisted of specialists in morphology, neurology, paleontology, dentistry and so forth. To preserve the external appearance, the dissection was restricted mainly to the viscera. The authors of this report joined in the dissection and observed the dental system of the fish. No available study of the teeth and surrounding tissues of the coelacanth was found in the literature, excepting Millot and AnTHONY's report[1]. However, their descriptions of the dental structures were unsatisfactory.

A jaw tooth and some gill teeth were studied with conventional histologic techniques presented in this report. The terminology used in this paper is shown in Fig. 1.

\section{Materials and Methods}

The coelacanth used for this study was captured in the sea near the Comores Islands in Mozambique Channel in December 1966 and fixed whole with a formalin solution. In July 1967, this fish was dissected at Tokyo. A right upper jaw tooth with a small portion of surrounding tissues and the second gill arch removed during the dissection provided materials for this study.

After the radiograms of the jaw tooth and the gill arch were taken from several directions, the jaw tooth and the gill arch with gill teeth were observed with the naked eyes.

Several gill teeth and the tip portion of the jaw tooth removed with a dental engine were embedded in plastic. Ground sections, 10-20 microns thick were prepared from this material with a thin sectioning machine. Contact historadiographs of the thin sections were made with a Softex CMR type low voltage X-ray unit.

On the other hand, the remaining jaw tooth and the gill arch with the attached teeth were decalcified with $5 \%$ nitric acid. After the tooth and the gill arch were

\footnotetext{
* 磯川宗七, 戸田善久, 久保田公雄：Department of Anatomy, Nihon Univ. School of Dentistry, Tokyo.
} 
embedded in celloidin, 20 microns thick serial sections were processed with conventional histologic techniques. These serial sections were stained with hematoxylin and eosin. SCHMORL's stain and PAP's silver stain were also employed.

\section{Observations}

Although the teeth of the coelacanth were observed in the vomer, palatine and sphenoid bones as well as other areas by MiLlot and ANTHONY, the authors of this report could observe only jaw and gill arch teeth, because the external appearance of this fish had to be preserved. In addition to the jaw and gill teeth, one could also see little hemispherical calcified structures called "denticles". The denticles contained the same histologic structures shown by the jaw and gill teeth.

\section{1) Visual Observation}

The several teeth which were found in the upper and lower jaws appeared conical in form and 5-8 $\mathrm{mm}$. in length. Many denticles were also detected near the jaw teeth (Fig. 2). An external view of the right upper jaw tooth was shown in Fig. 3. One can see four denticles on the labial side of the tooth.

The jaw tooth showed a glossy ivory color and seemed not to be covered with enamel or enamel like substance. The tooth was hard and had a sharp tip. The denticles seemed to be more hemispherical in the photograph (Fig. 3). However, detailed observation showed that they were conical in form and had a blunt tip.

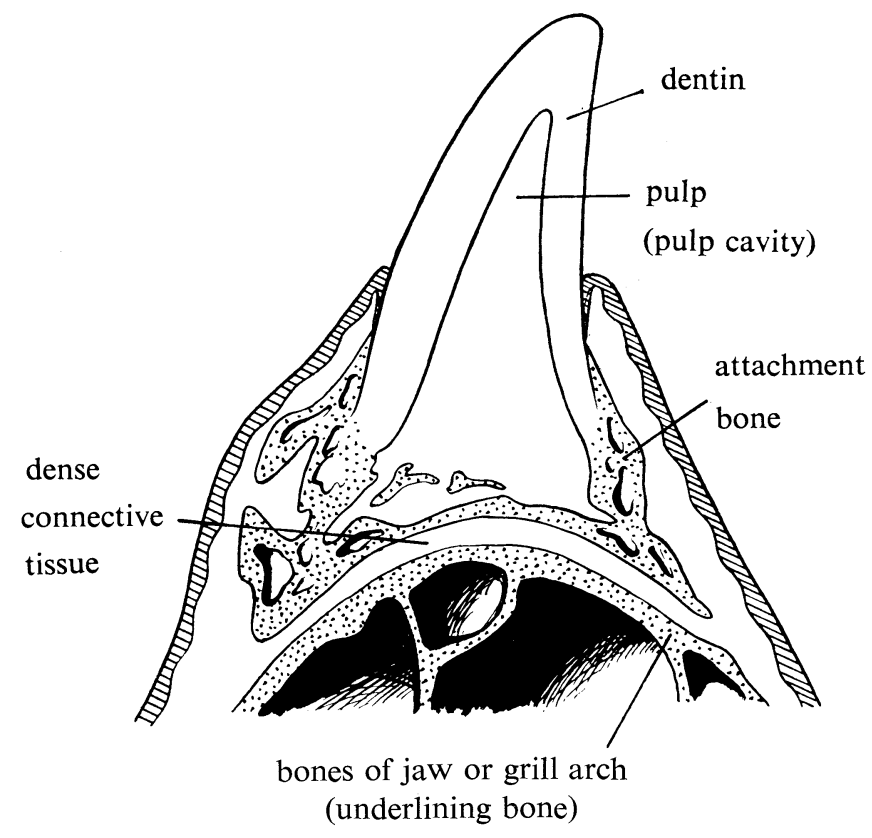

Fig. 1. The diagram illustrates a tooth of the coelacanth. 


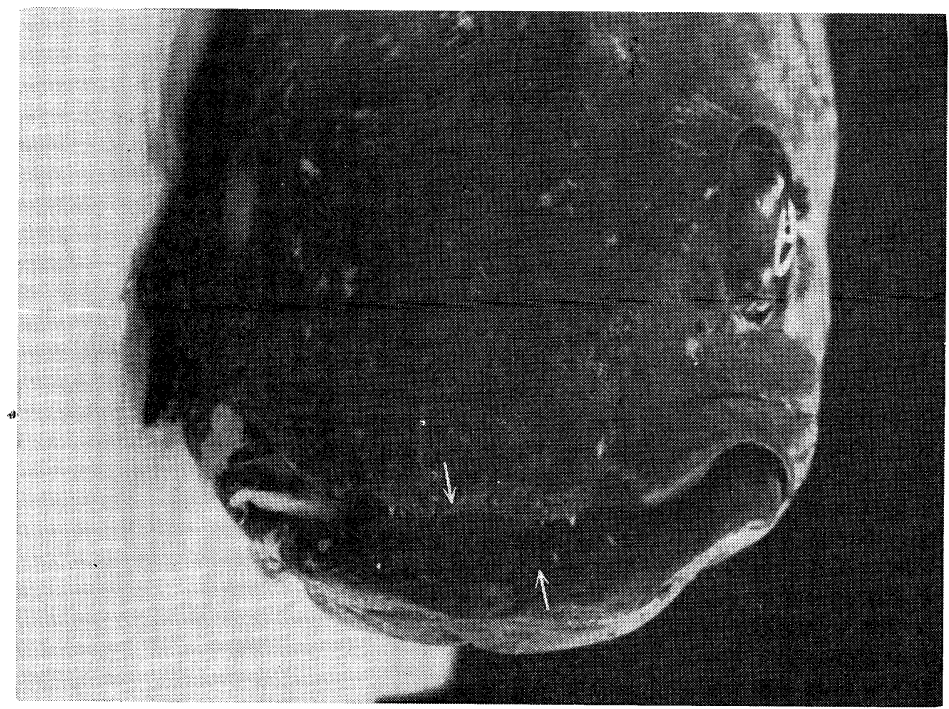

Fig. 2. The oral region of the coelacanth shows erupted teeth in the upper and lower jaws.

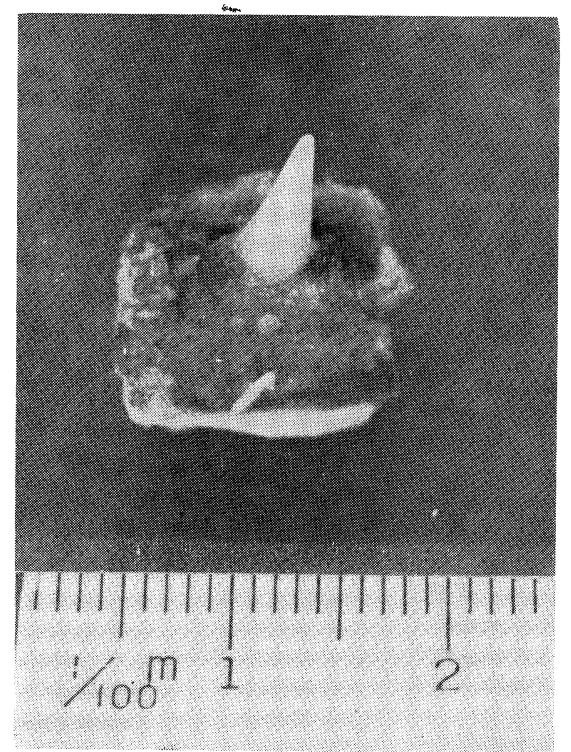

Fig. 3. A jaw tooth and four denticles are shown.

Although the right first and second gill arches were removed by the dissection, only the gill teeth erupted on the second gill arch were studied. The outer surface of the second gill arch upon which one can see many gill teeth arranged is shown in Fig. 4. The gill teeth were found on both surfaces of the gill arch and erupted in a cranial direction. Along the upper margin of the gill arch the teeth are arranged irregularly as shown in Fig. 5. The gill teeth like the jaw tooth were conical. What 
appeared to be tritubercular shaped teeth actually consisted of three closely approximated conical teeth (Fig. 4).

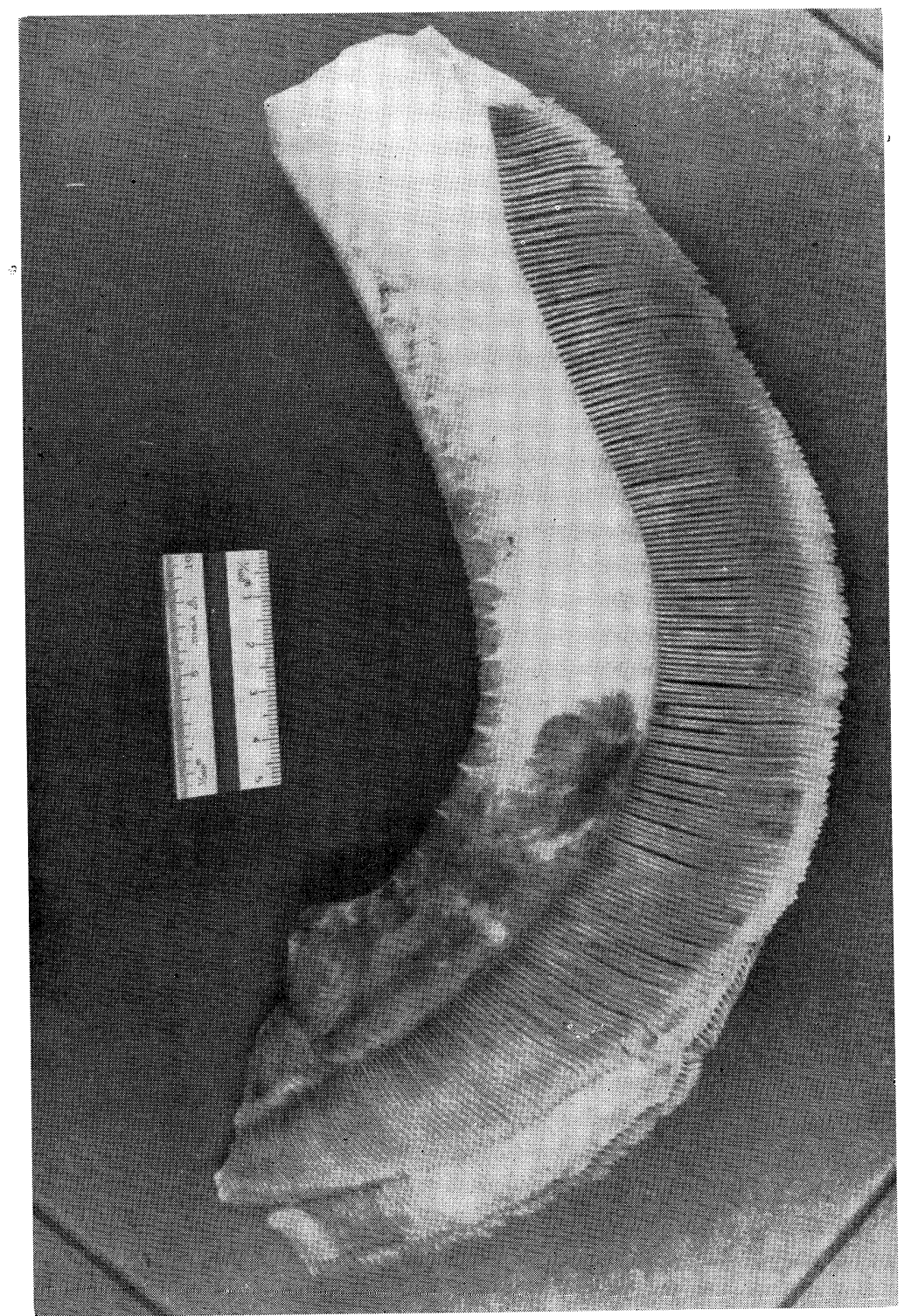

Fig. 4. The second gill arch shows many gill teeth.

The gill teeth were $6 \mathrm{~mm}$. in maximal length. Many denticles were also found on the gill arch. One could see through the mucosa that the gill arch was covered with small plates of the attachment bone. The small plates were arranged pavement like 


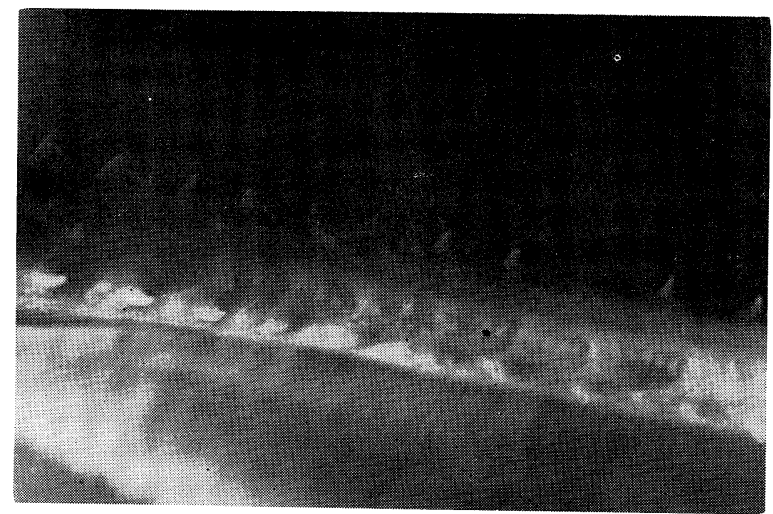

Fig. 5. Gill teeth are arranged on the surface of the inner arc of a gill arch.

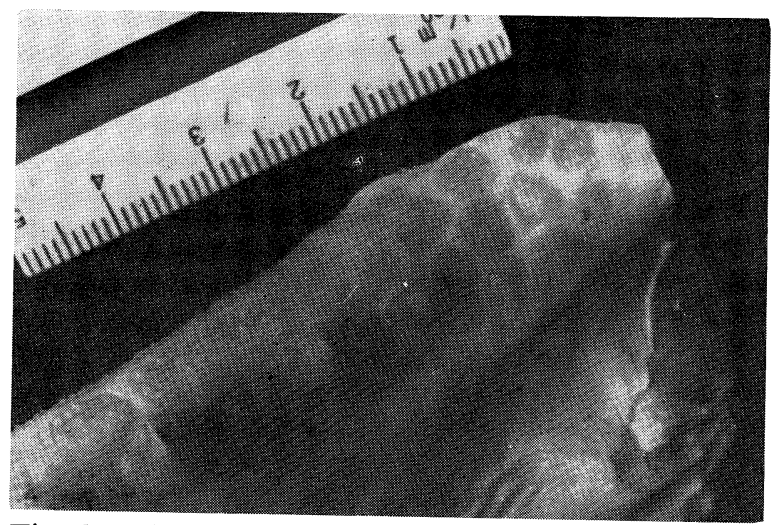

Fig. 6. The attachment bones seen through the oral epithelium contain many small gill teeth.

on the gill arch. The several teeth and denticles were implanted in the plates (Fig. 6). The gill teeth were also glossy ivory and had no enamel covering.

\section{2) Roentgen Observation}

A radiograph of the jaw tooth is shown in Fig. 7. The structural relation between the tooth and its attachment bone is not indicated in this picture. However, from this film a wide pulpal cavity and a thin layer of dental hard tissue are revealed. No hypercalcified tissue covering such as enamel was observed on the tooth surface.

The radiographic pictures of the gill arch are shown in Figs. 8, 9 and 10. The transverse section of the gill arch showed that the basal parts of the gill teeth were ankylosed to the attachment bone (Fig. 8). There was a soft tissue (connective tissue) attachment between the basal tooth bone and the bone of the gill arch. The gill teeth also had a wide pulpal cavity and did not have any hypercalcified tissue covering them.

Roentgen ray films of the outer and inner surfaces of the gill arch were also taken each with soft X-rays (Figs. 9 and 10). It was shown in the two X-ray pictures that the 


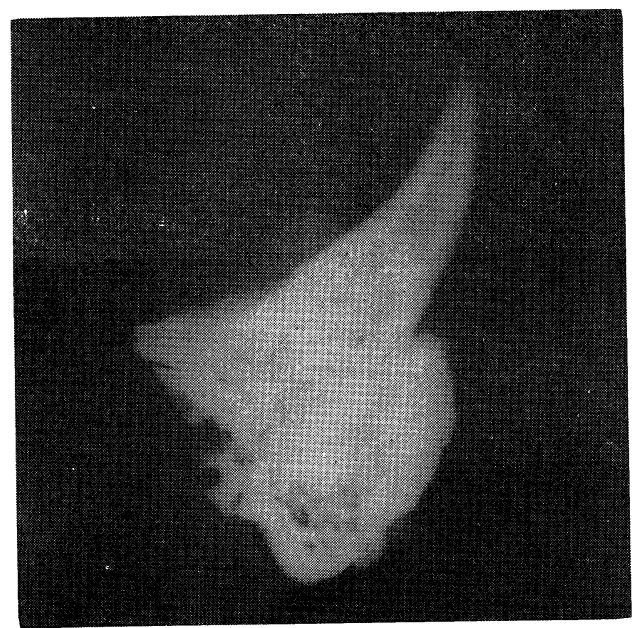

Fig. 7. A wide pulp cavity is shown in the radiogram of a jaw tooth.

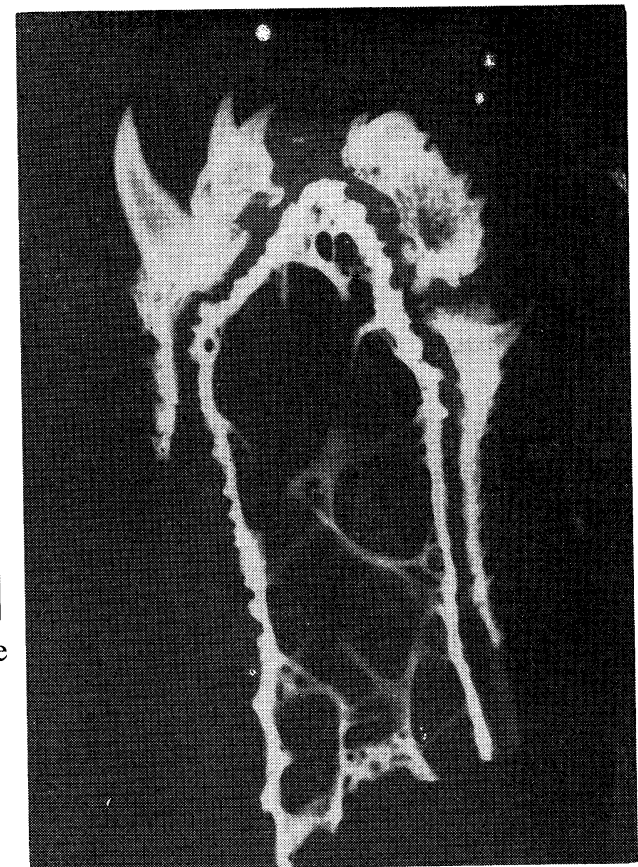

Fig. 8. A soft X-ray view of a cross section of a gill arch shows that the attachment bones are joined to the bone of the gill arch with soft tissue.

small bony plates were arranged like a pavement on the surface of the gill arch. These small bones were like the attachment bone, but the gill teeth were only found in the small bones near the upper margin of the gill arch. One or several teeth erupted from a small bone. When the tooth which showed a tritubercular form visually, was observed in these X-ray pictures, the tritubercular arrangement consisted of three conical teeth attached to the same attachment bone (Figs. 9 and 11). It became clear that no tritubercular teeth were detected in the coelacanth.

On the outer surfaces of the jaw and gill teeth, a radioopaque zone was revealed by a contact historadiograph (Fig. 12), nevertheless it did not show in the ordinary $\mathrm{X}$-ray film. The radioopaque zone was brittle and often broke away during the grinding process. No peritubular hypercalcified zone was found in the dentin of the teeth.

\section{3) Histological Observation}

a. Jaw tooth and gill teeth

A jaw tooth and the gill teeth consisted of a pulp and orthodentin, attached to a basal bone. Recognizable pulpal tissue occupied a wide pulp cavity. The basal end of the pulp tissue was bound to the attachment bone (Figs. 1 and 13). The materials used for this study were not fixed well enough to adequatly observe the pulp tissue. Nevertheless, a layer of odontoblasts were present along the dentin surface of the pulp 
Fig. 9. Outer surface

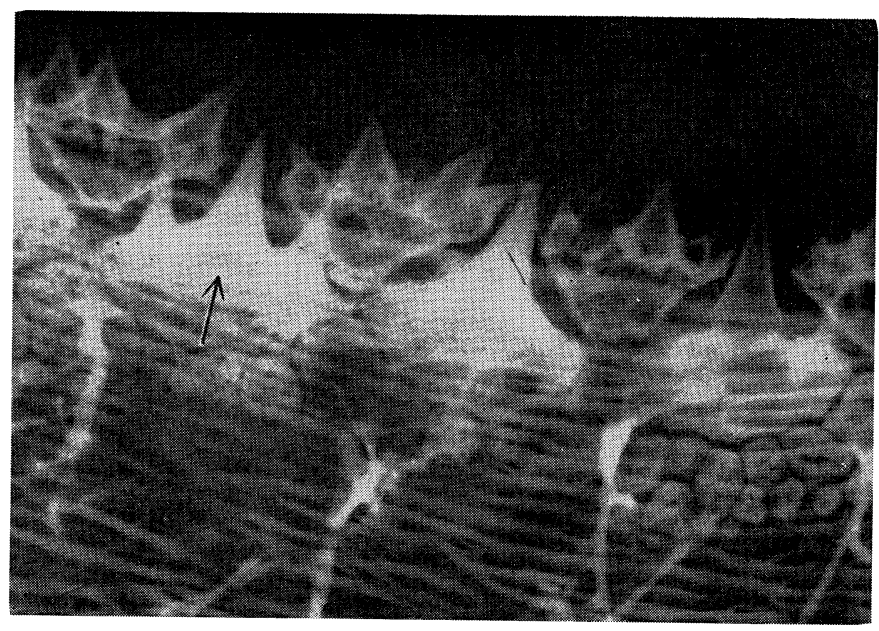

Fig. 10. Inner surface

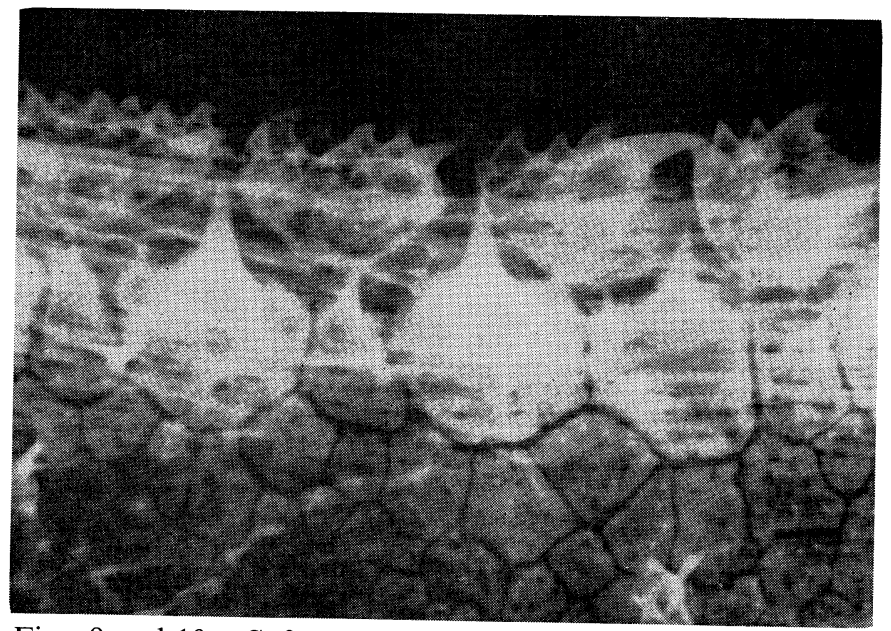

Figs. 9 and 10. Soft X-ray views show the inner and outer surfaces of a gill arch. Pavement like arrangements of the attachment bones with teeth are shown.

chamber. The odontoblastic cells had an oval nucleus and a hematoxylin affinitive nucleolus. The cytoplasm of the cells was slender in outline and stained pale red with eosin. The arrangement of the cells was not always regular.

There was a network of fibroblasts and blood vessels lined with squamous cells were seen in the pulp. The pulp tissue did not permit more precise observations because of diminished stainability. There was recognizable predentin in places along the junction of the dentin and the pulp tissue.

The dentin showed as a relatively thin layer in comparison with the wide pulp cavity. The dentinal tubules did not penetrate through the whole layer of the dentin. 


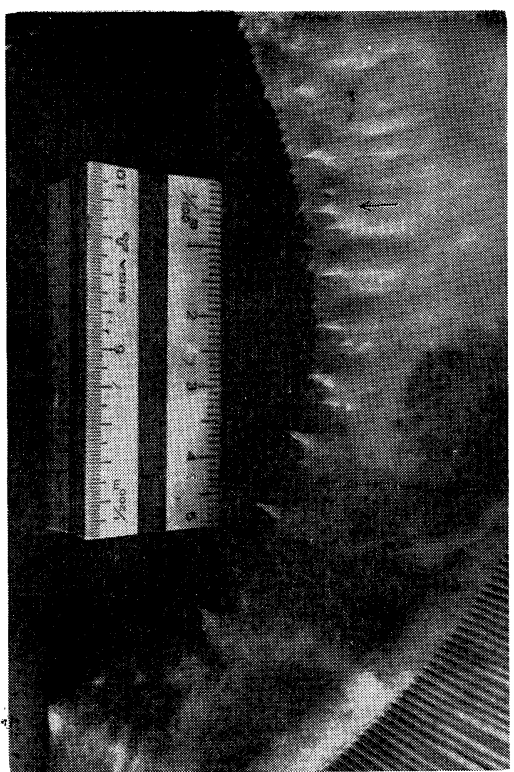

Fig. 11. The gill teeth seem to show tritubercular shapes.

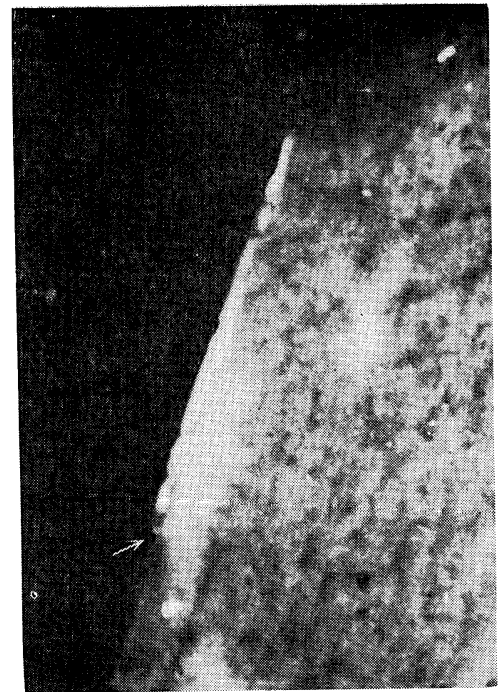

Fig. 12. The historadiograph of the tooth apparently shows a hypermineralized layer on the tooth surface. The layer broken off is seen at the bottom of picture.

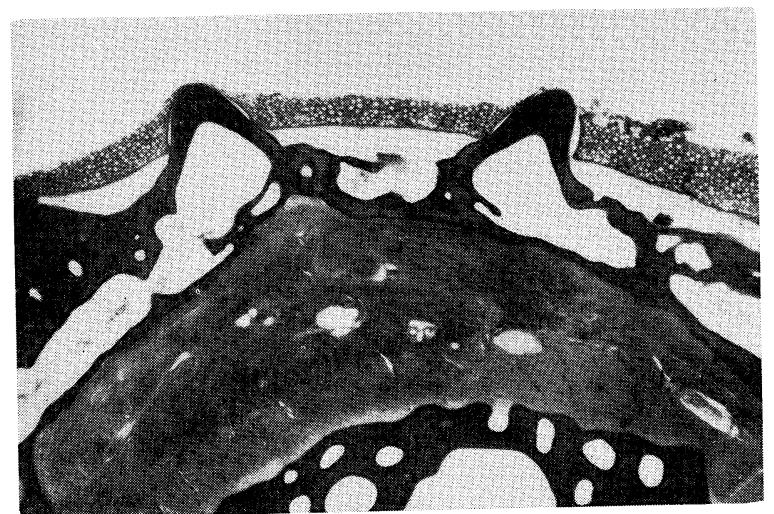

Fig. 13. Two gill teeth and their surrounding tissues are shown.

The tooth surface consisted of a very thin layer of tubeless dentin. The dentinal tubules were narrower and more irregular than those of the mammalian dentin (Fig. 14). The dentin was covered with a part of the attachment bone at the base. The junction of the dentin and the attachment bone was obscure. However, it was possible to roughly distinguish between them because the dentinal tubules could be seen especially in SCHMORL's stained sections.

Tissue irregularity was observed in the boundary layer between the attachment bone and dentin. Some of the canaliculi of the bone lacunae were in communication 


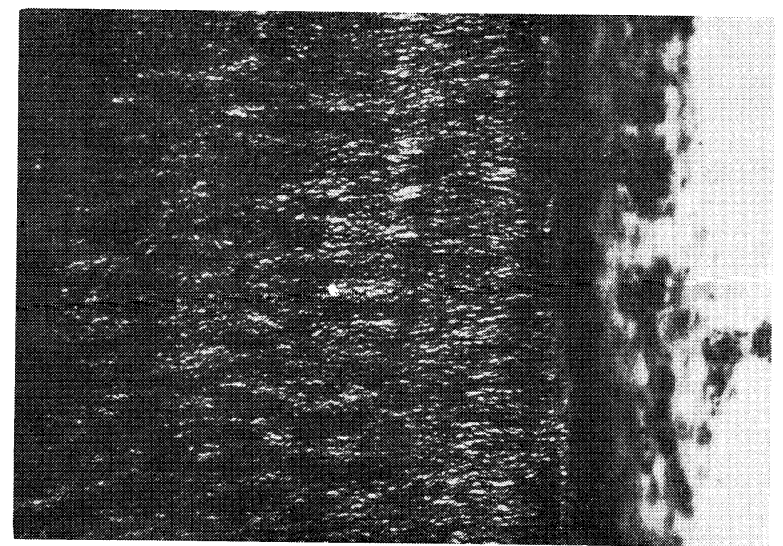

Fig. 14. Dentinal tubules are present in the dentin of a jaw tooth (SCHMORL's stain).

with dentinal tubules. Some dark incremental lines of VON EBNER were observed in the dentin stained with hematoxylin. A part of the dentin was covered with an epithelial attachment continuous with oral epithelium (Fig. 15). Both the oral epithelium and the epithelial attachment had many goblet like cells in their squamous cell layers.

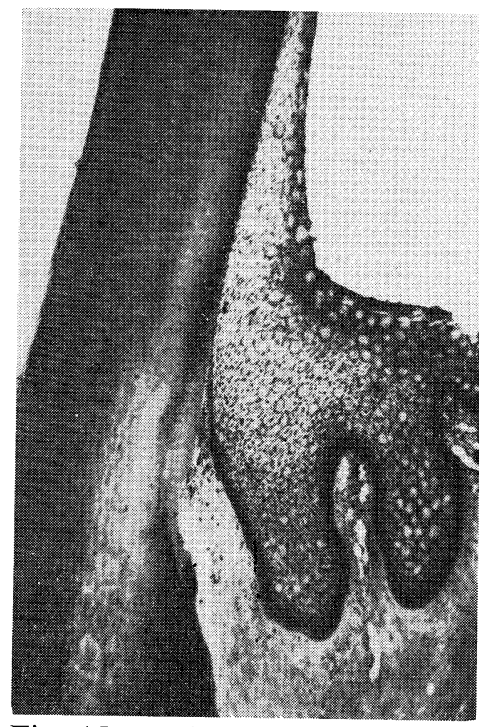

Fig. 15. Epithelial attachment in a gill tooth is shown.

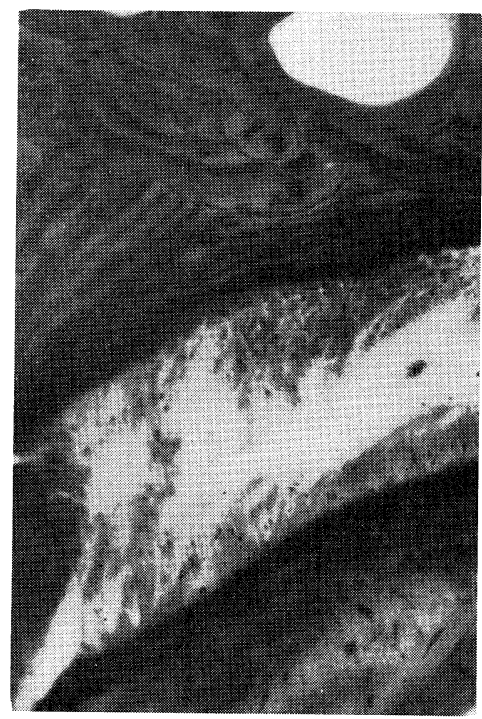

Fig. 16. The attachment bone has a lamellated structure.

\section{b. Surrounding structures of the tooth}

Teeth and denticles were each ankylosed at their bases with a bony plate or attachment bone. The attachment bone and the bones of the gill arch or jaw were 
joined to each other by connective tissue. Unlike the attachment bone of many teleostal fishes which show an acellular bone, the attachment bone of the coelacanth included osteocytes. The attachment bone itself was almost completely trabecular bone except for a thin layer of lamellated bone which was joined to the underlining jaw and gill arch bone by the connective tissue. Some of the bone trabeculae projected into the pulp cavity. The lamellated bone was well demarcated from the trabecular bone with clear lines of the bone lamellae. The osteocytes in the lamellated bone were arranged parallel to the bone surface toward the connective tissue. In just a small part of the right upper jaw used for this study, one could see evidence of remodelling of the bone (Fig. 16).

Loose connective tissue occupied spaces between the trabeculae. In it there were some blood vessels, connective tissue cells and fibers. The fibers were collagenous and did not form thick bundles. The fibers were also continuous as matrix fibers into the bone. However, the loose connective tissue did not show a typical bone marrow structure. Between the underlining bones and the attachment bones, there was dense connective tissue which was continuous with the periostal tissue of the two surfaces of the bones. The dense connective tissue showed a closer resemblance to a suture than to the periodontal ligament of a human dental system. A cross section of the connective tissue revealed that it was a dense connective tissue which could be subdivided into three zones (Fig. 17). The two outer zones, adjacent to the bones, consisted of parallel bundles of fibers arranged at right angles to the bones and continuing into the bone as SHARPEY's fibers (Fig. 18). An intermediate zone consisted of straight bundles of fibers arranged parallel to the suture, that is, bone surface. These fibers were collagenous and precollagenous. There were several interstitial spaces which contained a loose connective tissue and blood vessels, within the dense connective

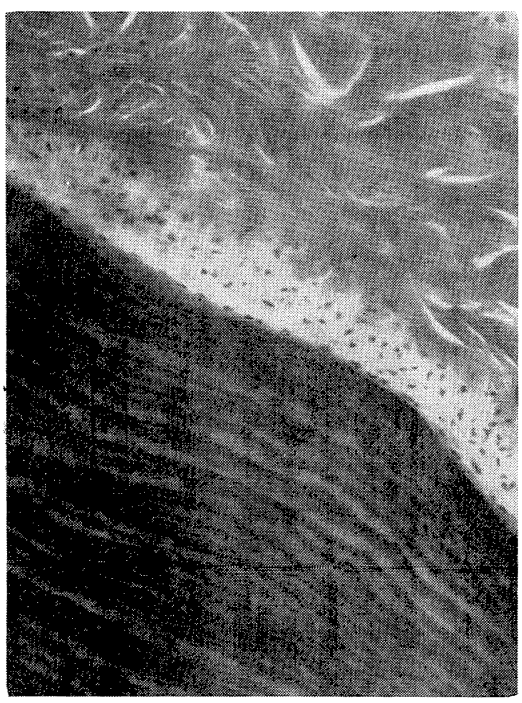

Fig. 17. Connective tissue separates the tooth attachment bone and the lamellated jaw bone.

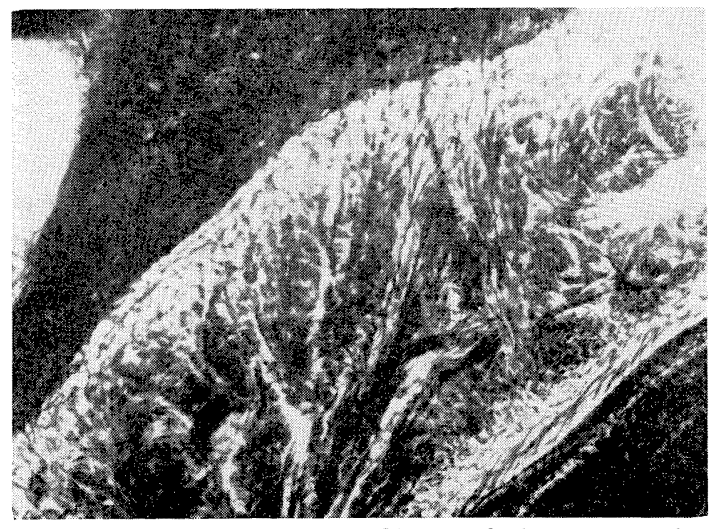

Fig. 18. The collagenous fibers of the connective tissue can be seen as SHARPEY's fibers invading the bone (PAP's silver stain). 


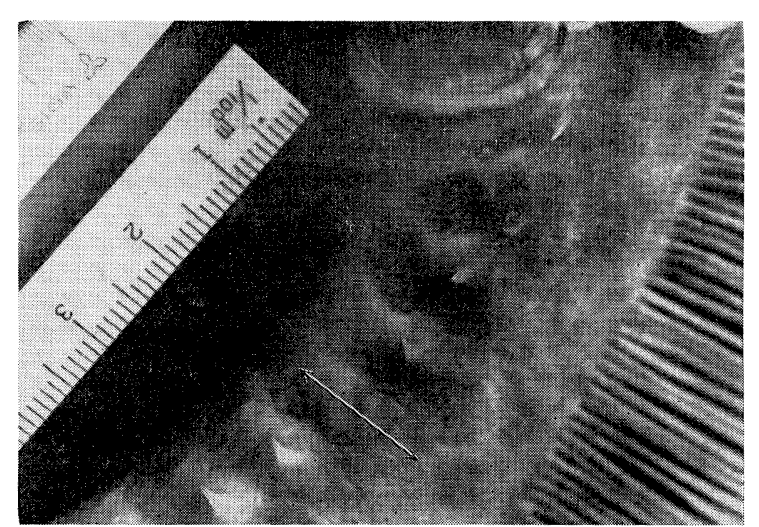

Fig. 19. A wound healed after exfoliation of a tooth.

tissue. Osteoblastic cells were found in the connective tissue along the bone margins. SHARPEY's fibers penetrated the bones between the osteoblastic cells. A layer of osteoid tissue stained with eosin was revealed along the surface of bones adjacent to the osteoblastic layer, but the osteoid layer along the attachment bone margin was obscure.

Underlining bones, jaw bone, and bone of the gill arch, consisted of compact and cancellous bones. The compact bone showed a lamellar structure (Fig. 17). The cancellous bone contained bony trabeculae and the bone marrow had been so altered that it consisted almost completely of fat tissue.

No developing tooth germs were found in the surrounding tissues of the jaw or gill arches. The region shown by an arrow in Fig. 19, was a wound formed by the shedding of a gill tooth. Histological observation of the wound, showed no succedaneous tooth germ in the underlining tissues. The bone defect under the wound was filled up with connective tissue.

\section{Discussion}

The present authors were very happy to have been able to have observed histologically, the teeth and surrounding tissues of this rare fish, the coelacanth. The fish had to be exhibited to the general public after it had been dissected. Therefore, regrettably, the histologic examination of both of the jaw and gill teeth could not be thorough. On the other hand, insufficient fixation of the fish did not permit accurate observations of the pulp tissue, intraosseous tissue and so forth.

It was revealed in this study that the dentin surface was not covered with a hypercalcified tissue. However, on some fish teeth which had no enamel cap a highly mineralized zone called Kragen by SCHMIDT[2] had been detected by TomEs[3] as well as Satomura[4] on the dentin surface. Such a highly mineralized layer on the dentin surface was also found in the historadiographs of the coelacanth's tooth. It was assumed that the tooth surface of the coelacanth was protected by increased mineralization because of certain external irritations. On the other hand, the fact 
that the jaw tooth had no cap of enamle or enamel like substance on its tip, might suggest that the coelacanth did not crunch shellfish, nor gnaw rock surfaces coated with sea weeds.

The jaw and gill teeth of the coelacanth were joined to the bone of the jaw or gill arch by the attachment bone and connective tissue. The teeth were ankylosed with the attachment bone. The attachment bone was neither an osteodentin found at the base of the Selachian tooth, nor a fibrous (acellular) attachment bone observed at the base of many osseous fish teeth. It was a cellular type bone having osteocytes. It seemed to be characteristic of the dental system of the coelacanth that the attachment bone consisted of cellular type bone.

Careful observation showed no evidence of replacement of the gill tooth which had been lost, probably as a result of injury. The resulting wound had healed with connective tissues. It was uncertain whether or not the jaw tooth was shed or exfoliated for the replacement by a new tooth, because there was insufficient tissue materials to adequately study the replacement of a jaw tooth.

The architecture of the connective tissue which consisted mainly of thick bundles of the collagen fibers and interstitial tissue areas, resembled a suture rather than a periodontal ligament. It was thought that perhaps the connective tissue functioned as a cushion for the teeth.

The teeth and the denticles of the coelacanth consisted of the pulp and orthodentin which contained dentinal tubules. According to the structures of the jaw, the gill teeth and their surrounding tissues, the teeth of coelacanth somewhat resembled Selachian rather than Teleostal fish teeth. The teeth of shark were composed of orthodentin type and osteodentin type according to Тпцкман[5] and IsoKAwA et al.[6]. The teeth of coelacanth were similar to the orthodentin type of the shark teeth. However, they differed from Selachian teeth in that an enamel like hypercalcified substance was not shown on the tooth surface of the coelacanth, and Selachian teeth had a base of dentin instead of the attachment bone. However, the dental system of the coelacanth presented a strong resemblance in its minute structure to the exoskeletons of the ostracoderm, Limulus and so forth.

From a phylogenetic viewpoint, it is believed that the dental system of coelacanth was a step in the evolutionary process from the exoskeleton of the ostracoderm to the teeth and their attachment in the selachi and bony fishes.

\section{Summary and Conclusion}

Jaw and gill teeth of a coelacanth (Latimeria chalumnal) were studied by means of a conventional histologic method. The teeth of this fish consisted of orthodentin and pulp. The tooth ankylosed with an attachment bone at their base. The attachment bone consisted of a cellular bone which was joined by a dense connective tissue with the jaw bone or the bone of the gill arch.

One could not find any enamel like substance of the dentin surface. However, historadiographs showed some surface hypermineralization.

The dense connective tissue between the attachment bone and the jaw bone or the bone of the gill arch, resembled that of a suture. 
No evidence of replacement of lost teeth was revealed.

It was concluded that the histological structure of the coelacanth's tooth comprised one of the steps in the evolution of the exoskeleton of the ostracoderm to the teeth and supporting structures of the bony and cartilagenous fishes.

Acknowledgements - The authors appreciate very much the permission given by Mr. Matsutaro Shoriki for the use of a rare fish coelacanth, and we are also particularly indebted to Professor Grant Van Huysen, Indiana University School of Dentistry and Dr. Tokiharu Abe, Tokai Regional Fisheries Research Laboratory, for many helpful suggestions.

\section{Reference}

[1] Millot, T. and Anthony, J.: Crossoptérygiens actuels; In Traité de Zoologie, Vol. 13, No. 3 , 2253 2597, 1958, Masson Co., Paris.

[2] Schmidt, W. J. and Kerl, A.: Die gesunden und die erkrankten Zahngewebe des Menschen und der Wirbeltiere im Polarisationsmikroskop; 141 184, 1958, Carl Hanser Verlag, München.

[3] Tomes, C. S.: Upon the development of the enamel in certain osseous fish; Phil. Trans. roy. Soc., Ser. B., Vol. 193, 35 46, 1900.

[4] Satomura, I: A study on outer dentin of teeth of some fish; Nihon Univ. dent. J., in press (Japanese).

[5] Гпцкман, Л. С.: ПОДКЛАСС ELASMOBRANCHII AKУ ЛOBЫE; OCHOBЫ ПАЛЕОНТОЛОГИИ, 196-261, 1964, ИЗДАТЕЛЬСТВО, МоскВа.

[6] Isokawa, S. and ABE, T.: A classification of Selachii; Nihon Univ. dent. J., in press (Japanese) 